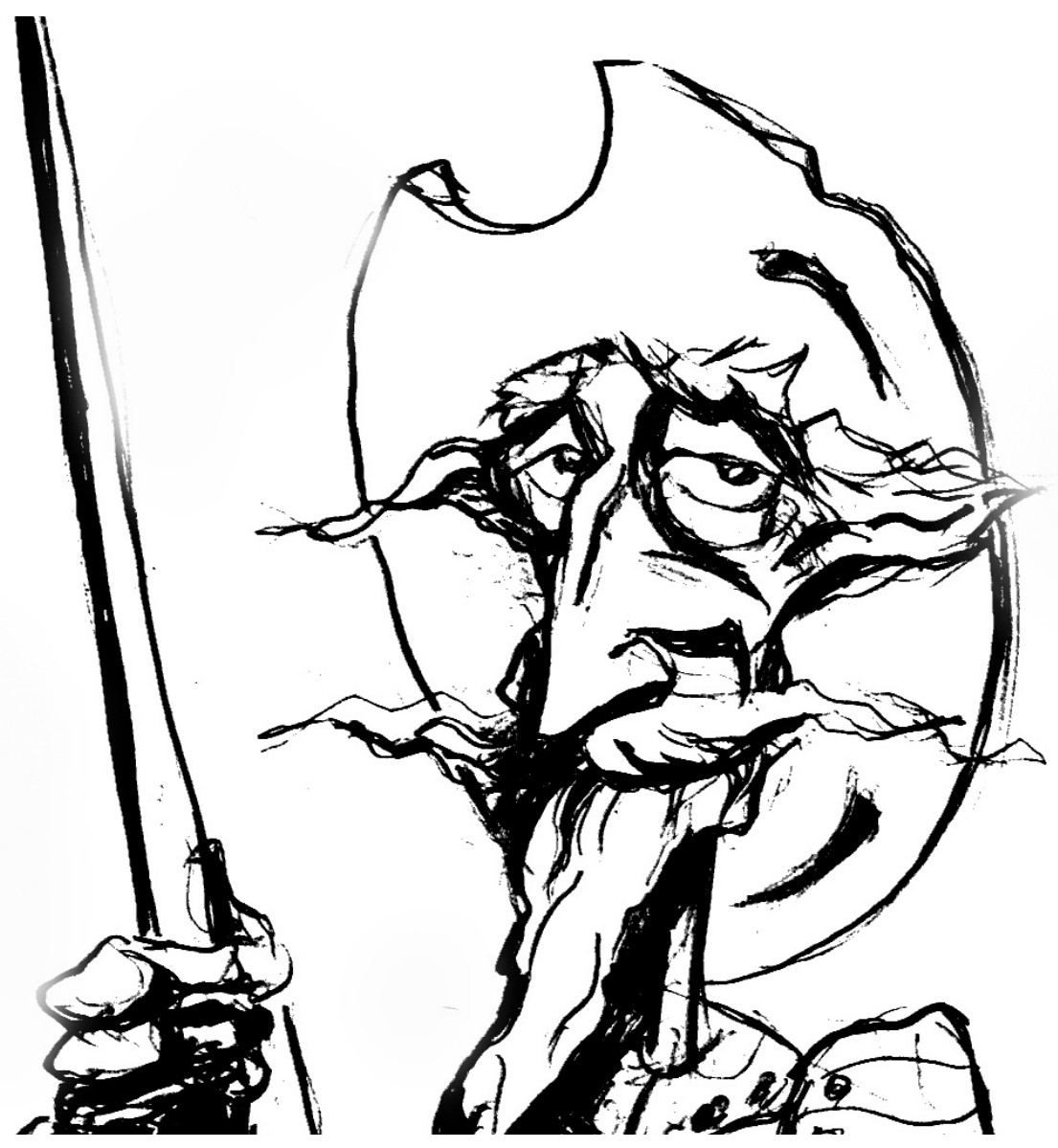

La fuga del Penal de Rawson, la Masacre de Trelew y las relaciones bilaterales entre Argentina y Chile. Tensiones y acercamientos durante la dictadura de Lanusse (agosto 1972)

[María Cecilia Míguez, Jorge Núñez] 



\title{
La fuga del Penal de Rawson, la Masacre de Trelew y las relaciones bilaterales entre Argentina y Chile. Tensiones y acercamientos durante la dictadura de Lanusse (agosto 1972)*
}

The Escape from the Rawson Prison, the Trelew Massacre and the Bilateral Relations between Argentina and Chile. Tensions and Approaches during the Dictatorship of Lanusse (August 1972)

\author{
MARÍA CECILIA MíGUEZ \\ JORGE NÚÑEZ
}

\section{Resumen}

El objetivo general del trabajo es complejizar la mirada sobre las relaciones internacionales de los últimos años de la autodenominada Revolución Argentina, vinculando los conflictos internos de esa dictadura argentina con la política exterior respecto de los países de la región, en este caso, con Chile, en el contexto particular del gobierno de Salvador Allende, que tenía por propósito la transición al socialismo. Para ello, estudiaremos archivos diplomáticos y de prensa de ambos países en torno al conocido hecho de quienes abandonaron el país en un avión que los condujo a Santiago de Chile y con posterioridad a La Habana.

Palabras Clave

Lanusse; Argentina; Chile; Trelew; guerrilla

\begin{abstract}
The general objective of the work is to make the international relations of the last years of the selfproclaimed Argentine Revolution more complex, linking the internal conflicts of that Argentine dictatorship with the foreign policy towards the countries of the region, in this case, with Chile, in the particular context of Salvador Allende's government, whose purpose was the transition to socialism. To this end, we will study diplomatic and press archives of both countries around the well-known fact of those who left the country in a plane that took them to Santiago de Chile and later to Havana
\end{abstract}

Keywords

Lanusse; Argentina; Chile; Trelew; guerrilla

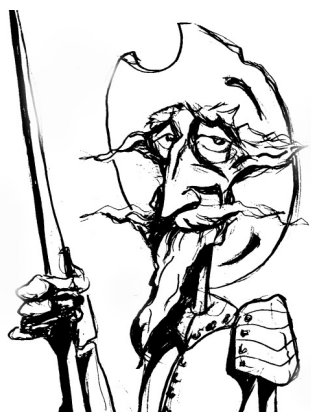

Recibido con pedido de publicación el 15 de diciembre de 2019

Aceptado para su publicación el 8 de febrero de 2020

Versión definitiva recibida el 23 de abril de 2020

María Cecilia Míguez, Consejo Nacional de Investigaciones Científicas y Técnicas, Universidad de Buenos Aires, Buenos Aires, Argentina; e-mail: mmccmiguez@gmail.com

Jorge Núñez, Consejo Nacional de Investigaciones Científicas y Técnicas, Universidad de Buenos Aires, Buenos Aires, Argentina; e-mail: jorgealber75@gmail.com

* Agradecemos a los evaluadores del artículo por los comentarios y sugerencias

Esta obra se publica bajo licencia Creative Commons. Atribución-NoComercial-CompartirIgual $($ (c) EY-NC-SA $\underline{4.0 \text { Internacional }}$

Míguez, María Cecilia y Núñez, Jorge "La fuga del Penal de Rawson, la Masacre de Trelew y las relaciones bilaterales entre Argentina y Chile. Tensiones y acercamientos durante la dictadura de Lanusse (agosto 1972)", Prohistoria, Año XXIII, núm. 33, jun. 2020, pp. 203-231. 


\section{Introducción ${ }^{1}$}

Los últimos años de la autodenominada Revolución Argentina se caracterizaron por un cambio de rumbo en la inserción internacional argentina y en la política exterior. A diferencia de la política llevada adelante por Juan Carlos Onganía (1966-1970), que implicaba en varios aspectos económicos e ideológicos una alineación con los Estados Unidos, -aunque no en modo automático debido a la heterogeneidad de la coalición que conformaba el gobierno de facto-, Alejandro Agustín Lanusse relativizó la concepción de las "fronteras ideológicas", e inició una serie de nuevas políticas que incluyeron la "apertura hacia el este", el reforzamiento de la relación con el Chile socialista de Salvador Allende y el acercamiento al Pacto Andino como estrategia de integración regional. Prueba de esto último fueron los encuentros bilaterales entre ambos presidentes y la Declaración de Salta, que estudiaremos.

En el plano interno, a pesar de que fue el período en el que se decidió reabrir el proceso electoral, se trataba de una dictadura que recrudecía la estrategia represiva y uno de los hitos del carácter violento del gobierno fue el fusilamiento, el 22 de agosto de 1972, de dieciséis militantes de las organizaciones armadas ERP (Ejército Revolucionario del Pueblo), Montoneros y FAR (Fuerzas Armadas Revolucionarias), que fracasaron en el intento de fuga de la cárcel de Rawson producido una semana antes.

Es conocido el éxito de quienes efectivamente lograron abandonar el país tras secuestrar un avión de la compañía Austral que los condujo a Santiago de Chile (y que con posterioridad se dirigieron a La Habana) pero menos se ha indagado en el impacto diplomático de esa circunstancia, en el contexto del relativo acercamiento bilateral entre Argentina y Chile, objeto de esta ponencia. Para ello, estudiaremos archivos diplomáticos argentinos y chilenos y haremos un relevamiento de la prensa de algunos países latinoamericanos y de Cuba, ya que la isla fue, como afirmábamos, el destino de aquéllos que sí lograron fugarse.

En suma, el objetivo general del trabajo es complejizar la mirada sobre las relaciones internacionales del período, vinculando los conflictos internos de esa dictadura argentina con la política exterior respecto de los países de la región, en este caso, con Chile, en el contexto particular de un gobierno que tenía por propósito la transición al socialismo. El enfoque que este trabajo pretende aportar es el de incluir actores diversos en la interpretación de las relaciones internacionales, vinculando fenómenos políticos y sociales del orden interno a

\footnotetext{
${ }^{1}$ Este trabajo es parte de las investigaciones realizadas en el marco del Proyecto PIP (2015-2017) dirigido por María Cecilia Míguez, "Los condicionantes internos de la inserción internacional argentina. Presiones, debates y movilizaciones en torno a la política exterior desde la década de 1960 hasta la actualidad" y del Proyecto UBACyT (2018-2020) "Política exterior, inserción económica internacional y movilización popular (1966-2016)".
} 
la comprensión global de los vínculos exterior: interpretar los fenómenos diplomáticos en un contexto de complejidad, abandonando las caracterizaciones lineales y las miradas que se centran exclusivamente en los aspectos interestatales.

\section{La política exterior en los inicios de los años 70': Argentina y Chile}

En el caso de Chile, en las elecciones de 1970 triunfó la coalición popular que llevó al poder a Salvador Allende, con la dificultad de que ese gobierno no tendría mayoría parlamentaria. A partir de allí se llevó adelante la denominada "vía pacífica" (o vía chilena) al socialismo, un programa de reformas que incluyó expropiaciones que atentaron contra el poder del latifundio, la constitución de cooperativas de campesinos como base de la nueva política agraria, el control de algunos bancos y actividades industriales y una significativa redistribución del ingreso (Ansaldi y Giordano, 2014: 407).

Ya durante la presidencia de Eduardo Frei (1964-1970), y en el marco del alineamiento continental con los Estados Unidos y la Doctrina de Seguridad Nacional, se habían reestablecidos lazos consulares y diplomáticos con la Unión Soviética (URSS), Checoslovaquia, Hungría, Bulgaria, Polonia, Rumania y con todo el resto de los países satélites, excepto Albania y la República Democrática Alemana. Ello condujo al intercambio de numerosas misiones comerciales y a ciertos convenios de cooperación, como el caso de un crédito otorgado por la URSS en 1968. En efecto, la rivalidad de la Guerra Fría y la disputa por los mercados latinoamericanos operaba como sustrato para la diversificación de las relaciones internacionales. La línea sostenida en el Consenso de Viña del Mar (1969) profundizaría esa orientación, promoviendo un acercamiento a Cuba y constituiría un importante antecedente para la afirmación de nuevas orientaciones en el plano latinoamericano.

El gobierno de Allende intentó recostarse en las relaciones con la Unión Soviética, pero no obtuvo el suficiente apoyo económico, si bien tal como analiza Joaquín Fermandois, la URSS estaba interesada en las relaciones económicas - pero siempre en el marco de considerarlo un país en desarrollo y no un país socialista- y en ofrecer créditos a los sectores militares para "peruanizarlos" (1998: 170). ${ }^{2}$

Más allá de las mencionadas diferencias, en cuanto al escenario regional, Chile, Perú y Ecuador formaban parte del recientemente puesto en marcha

\footnotetext{
2 El proceso peruano se caracterizaba por un gobierno militar de nacionalismo autoritario que buscó pivotear con la relación con la Unión Soviética para generar márgenes de autonomía en su política económica e internacional luego de los conflictos con los Estados Unidos. Las medidas nacionalistas y desarrollistas fueron llevadas adelante por un sector de los militares, así como toda la política exterior tendiente a cuestionar el poder de los Estados Unidos en la región (Míguez, 2018).
} 
Pacto Andino, una estrategia de integración particular que priorizaba el crecimiento y el impulso a la industrialización sustitutiva y la planificación estatal como herramienta central del desarrollo. Constituía un modelo alternativo al de la Asociación Latinoamericana de Libre Comercio (ALALC), donde había finalmente hegemonizado la estrategia comercialista. ${ }^{3}$

El Pacto Andino se constituyó como una respuesta crítica a las asimetrías que pervivían en el marco de la ALALC. Nacido del Acuerdo de Cartagena de 1969, tuvo desde sus inicios -en especial para Perú y Chile, y luego Venezuela desde su incorporación- la aspiración de constituirse en una alianza política donde el carácter antiimperialista tuvo un rol importante. Tal como afirmaría el presidente peruano Velasco Alvarado, el acuerdo era una herramienta para el fin de la subordinación a la hegemonía de los poderes centrales del sistema internacional (Brands, 2010: 477).

Por su parte, la dictadura militar autodenominada Revolución Argentina, como las otras en la Argentina, constituyó un gobierno heterogéneo y también disputado. Ese gobierno tuvo tres presidencias de facto: la primera, la de Juan Carlos Onganía, luego un breve interregno de Roberto Marcelo Levingston y finalmente el gobierno de Alejandro Agustín Lanusse.

Los últimos años de ese período dictatorial, período en el que se enmarca nuestra investigación, se caracterizaron por un cambio de rumbo en la inserción internacional argentina y en la política exterior. El escenario de recrudecimiento de la competencia entre las potencias del mundo bipolar por el dominio de los mercados en todo el globo, incluida América Latina se reflejó también en el seno del estado y del gobierno dictatorial. A diferencia de la política llevada adelante por Onganía (1966-1970), que implicaba en varios aspectos económicos e ideológicos una alineación con los Estados Unidos, -aunque no en modo automático debido a la heterogeneidad de la coalición que conformaba el gobierno de la denominada Revolución Argentina-, ${ }^{4}$ Lanusse relativizó la concepción de las "fronteras ideológicas", e inició un giro en la política económica que se expresó en la firma de un acuerdo comercial con la Unión

\footnotetext{
${ }^{3}$ Para un análisis de las estrategias en debate en oportunidad de la conformación de la ALALC ver Musacchio (2006).

${ }^{4}$ En cuanto a la caracterización de los vínculos entre el gobierno de Onganía y los Estados Unidos existen una serie de trabajos que discuten el grado de afinidad o alineamiento. Se coincide aquí con Rapoport y Laufer (2000) quienes afirmaron que a pesar de que el Departamento de Estado demoró 18 días en reconocer al gobierno de facto en función de las diferencias entre la CIA, el Pentágono y el propio Departamento, "en el plano de las relaciones internacionales se abrió el período de mayor proximidad a los intereses económicos y geopolíticos de los Estados Unidos en la historia argentina. De otra parte, Cisneros y Escudé (2000) consideran que la política llevada adelante por Onganía no debe interpretarse como alineada directamente con los Estados Unidos - sino más bien como anticomunista y antisoviética- ni tampoco debe afirmarse la existencia de una ruptura abrupta respecto del período de Lanusse.
} 
Soviética en 1971 con cláusula de nación más favorecida para ambas partes y en el establecimiento de relaciones diplomáticas con la República Popular China en 1972. A ello se sumarían las citadas visitas al Chile de Allende. Durante el mandato de Onganía había surgido un acercamiento inicial con su par Eduardo Frei, que se vio entorpecido por varias cuestiones, entre ellas el fallo británico emitido en diciembre de 1966 sobre la disputa limítrofe por la zona de Río Encuentro (favorable a la Argentina) y unos incidentes en la zona del Canal de Beagle. Una serie de Declaraciones Conjuntas intentaron reestablecer el clima bilateral pero no lo lograron. Las relaciones comenzaron a destrabarse con la breve asunción de Levingston, dado el carácter heterodoxo de sus afirmaciones políticas y la asunción de Salvador Allende. Ante la victoria de la izquierdista Unidad Popular el general Levingston reiteró la política de no intervención (Cisneros y Escudé, 2000). Visto retrospectivamente, eso allanaba el camino a la nueva orientación a la que nos referíamos del general Lanusse. En esto se distanciaría de la posición asumida por Brasil, que se convertiría en actor central del golpe del estado promovido y apoyado por los Estados Unidos contra Allende el 11 de septiembre de 1973 (Moniz Bandeira, 2011). El trabajo de Tanya Harmer (2013) aborda con gran detalle estos sucesos, construyendo un complejo escenario donde varios actores, no solamente los Estados Unidos, competían por el predominio de sus intereses en la región, abriendo espacio a una Guerra Fría “interamericana”.

Por otra parte, por diversos factores, una poderosa fracción de la clase dominante argentina comenzó a promover desde 1970 la negociación de un tratado comercial con la Unión Soviética. Entre esos factores se encontraban los intereses de negocios vinculados a dicha superpotencia que habían venido creciendo desde el período desarrollista, y las dificultades para colocar los productos en la Europa Comunitaria. Este viraje culminará en una nueva relación triangular hacia mediados de la década de 1970, consolidado por la dictadura militar implantada en 1976, ocupando la Unión Soviética durante unos años el vértice anteriormente cumplido por Europa occidental y antaño por Inglaterra. ${ }^{5}$ Ello no implicaba una transformación ideológica ni el abandono de la noción del enemigo interno comunista -se trataba de un gobierno dictatorial dispuesto a perseguir y reprimir toda manifestación política volcada hacia la izquierda- sino de alineamientos internacionales y de proyectos de inserción y de acompañar pragmáticamente la decisión de abrir nuevamente el proceso electoral. Recordemos que las disposiciones arancelarias y paraarancelarias dispuestas por la Comunidad Económica Europea tenían un impacto directo sobre las exportaciones argentinas que buscarían reorientarse hacia los países socialistas. Asimismo, los intentos de apertura se vinculaban con la política de distensión de Nixon y también con el proceso político interno

\footnotetext{
${ }^{5}$ Para las relaciones bilaterales entre la Argentina y la Unión Soviética en el período ver Rapoport (1995a) y Laufer y Spiguel (1998).
} 
en las Fuerzas Armadas Argentinas. ${ }^{6}$ En este sentido, el canciller Luis María De Pablo Pardo -ministro de los gobiernos de facto entre 1970 y 1972- afirma lo siguiente en una entrevista recientemente publicada:

“...la ruptura de las fronteras ideológicas supone también la ruptura con la Doctrina de la Seguridad Nacional, más teniendo en cuenta que hay una situación interna explosiva. Se había producido ya el "Cordobazo". La situación estaba caldeada. Comienza a visualizarse dentro de los comandantes en jefe un cambio en ese sentido. Usted lo ve en las reuniones, la Doctrina de Seguridad Nacional no va más o es algo que está un poco perimido, hay que empezar a ir cambiando. Esto es una cosa que ocurre en el período de Lanusse, no en el período de Levingston. (De Pablo Pardo, 2016: 365)

Por estas razones, varios autores han coincidido en afirmar que Lanusse inició lo que se conoce como "apertura hacia el Este". Esa apertura coincidió con un acercamiento a los países del Pacífico, dentro de ellos Chile y en general a los del Pacto Andino. ${ }^{7}$ En efecto existieron durante el mandato de Onganía, importantes acuerdos con el país vecino, pero el entendimiento mayor se dará recién durante la presidencia de facto de Lanusse, cuyo punto culminante serán la firma del Compromiso sobre Arbitraje en Londres y la Declaración de los presidentes Lanusse y Allende en Salta, ambos en julio de 1971.

En Salta se produjo la primera de las visitas mutuas y los mandatarios firmaron la conocida Declaración, el 24 de julio de 1971, donde, entre otros elementos a los que nos referiremos, aparece por primera vez el concepto del "pluralismo ideológico". Un mes antes los cancilleres Luis María de Pablo Pardo y Clodomiro Almeyda Medina habían firmado el Acta de Santiago sobre Cuencas Hidrológicas en la ciudad de Santiago.

La justificación de la noción del pluralismo ideológico provenía -en el más conciliatorio de sus sentidos- de la hipótesis de la coexistencia pacífica, es decir, la idea de que el desarrollo nuclear de ambas potencias había abierto un período donde ambos polos del sistema internacional debían ser cautelosos y prudentes en sus confrontaciones, y que dicha coexistencia se habría manifestado activa y pasivamente, llegando a un punto culminante en 1972, con el tratado sobre limitación de los sistemas misiles antibalísticos (Carella y Moneta, 1973: 118-119). Varios elementos de la política exterior y de las

\footnotetext{
6 Se relaciona con la visita de Nixon a China en 1972 en el contexto de la denominada diplomacia del ping pong y esa etapa de relativa distensión, sin embargo, las misiones comerciales a la URSS son anteriores -en 1970- y el acuerdo firmado por Antonio Estany Gendre fue en junio de 1971. Ver Rapoport (2016).

7 Paradiso (1993) afirma que la importancia de la proyección hacia América Latina figuraba ya en los enunciados del Proyecto Nacional propuesto por el CONADE-CONASE.
} 
relaciones internacionales e interamericanas del período, fueron amalgamando una nueva posición latinoamericana -aunque heterogénea- que tuvo un importante alcance en los primeros años de la década, y que se vería luego arrasada con el avance de las dictaduras promovidas por los Estados Unidos. Esa posición encontraría en la aspiración del pluralismo ideológico, la afirmación del antiimperialismo.

En oportunidad de la citada Declaración de Salta, Lanusse y Allende manifestaron su voluntad de impulsar "la integración física, económica y científica", al igual que el compromiso de fortalecer los vínculos de amistad entre ambos pueblos, basados en la histórica resolución pacífica y jurídica de las diferencias y en el respeto al "pluralismo político". La declaración incluía también la necesidad de incrementar los intercambios comerciales entre ambos países destacando la importancia que en los mismos debía alcanzar el sector industrial. En dicha declaración conjunta ambos presidentes reiteraron "el respeto al pluralismo político en la comunidad internacional", expresaron "su firme voluntad de continuar fortaleciendo los vínculos de amistad entre sus pueblos, no interrumpidos desde que ambas naciones alcanzaron su independencia". Esta amistad, "ha tenido sus bases de sustentación en el respeto a los principios de no intervención en los asuntos internos y externos de cada Estado y en la voluntad siempre sostenida de resolver sus problemas por la vía pacífica y jurídica" (Declaración de Salta, 1971: 133).

Lanusse incluso afirmó que la Argentina estaba "dispuesta a guiar sus relaciones exteriores con un amplio criterio de universalidad, que no admite restricciones impuestas por prejuicios o tabúes ideológicos" (Scena, 1981: 214215).

En oportunidad del viaje del dictador argentino a Santiago de Chile, Allende declaró en su discurso de recibimiento:

“Reafirmamos, sobre todo, el respeto al pluralismo político en la comunidad internacional y el derecho de cada Estado de mantener relaciones con los países que estiman conveniente. En las Declaraciones Conjuntas que hemos venido firmando, también hemos dado relevancia especial al derecho de los Estados a recuperar sus riquezas básicas y también, como usted y el Presidente Velasco Alvarado acaban de declarar "el derecho soberano de cada país de disponer libremente de sus recursos naturales." (Allende, 1971: s/n)

La posición de Lanusse, a diferencia del caso chileno, y de otros países latinoamericanos, no refería al antiimperialismo. Tal como destaca en sus trabajos Alfredo Azcoitia (2017) la postura de Lanusse reflejaba la aspiración de algunos sectores económicos que observaban en la estrategia de vinculación con los países del Pacífico una posibilidad de impulsar determinadas industrias 
locales. La otra cara de esa estrategia era la búsqueda de apoyos relativos en la Unión Soviética, que como ya se mencionó no impedía que en el plano interno se tratara de una dictadura dispuesta a perseguir, reprimir y hasta fusilar a sus opositores. Lejos estaba -en términos políticos- de la visión política del pluralismo ideológico impulsada por su par chileno.

Luego de esos primeros encuentros con Allende, y en el marco del acercamiento al Pacífico, Lanusse iniciaría una importante gira como estrategia de acercamiento a los países del Pacífico (Míguez, 2019).

\section{La fuga de Rawson y la masacre de Trelew ${ }^{8}$}

A pesar de la estrategia económica y de las relaciones internacionales impulsada por Lanusse, la dictadura militar recrudecía brutalmente su estrategia represiva. Tal como afirma Cheren (1997), Lanusse inaugura su asunción en 1971 con el secuestro de Mirta Cortese, víctima de torturas salvajes, que ya eran moneda corriente en la Argentina al igual que los secuestros: el intento de rapto de Roberto Quieto, el matrimonio Verd que jamás aparecería, Juan Pablo Maestre -que aparecería muerto al día siguiente en Luján. A fines del mes de julio tres organizaciones armadas peronistas de Córdoba ejecutan al director de la prisión, acusado de haber torturado cruelmente a varios presos políticos. La respuesta del gobierno es recrudecer la represión. La actividad sindical es duramente perseguida. El gobierno instala la Cámara Federal Penal, encargada de juzgar a los subversivos, en el mes de noviembre de 1971. Para 1972 la escalada represiva no se detiene.

Como afirma Ariel Eidelman (2009), para inicios de la década de 1970, las cárceles argentinas "se llenaron de presos" (2009: 13). Las movilizaciones populares -principalmente el gran estallido obrero-estudiantil en Córdoba en mayo de 1969-, el surgimiento y consolidación de las organizaciones armadas (en especial, pero no únicamente, el PRT-ERP y Montoneros) y la legislación represiva sancionada por la dictadura militar de la Revolución Argentina, habían colmado la capacidad de los establecimientos de reclusión en el país.

Aunque privados de su libertad, los presos políticos (a diferencia de los "comunes"), implementaron un régimen espartano que incluía lecturas de autores clásicos del marxismo, discusión sobre la coyuntura política y ejercicios de gimnasia diarios.

Las cárceles eran un hervidero y el Penal de Rawson en la lejana y despoblada provincia de Chubut, no fue la excepción. A inicios de 1972, estaban detenidos allí los principales líderes del PRT- ERP (Mario Roberto Santucho,

\footnotetext{
8 El tema ha sido extensamente abordado, escapa a los alcances de esta ponencia. Para una lectura ineludible ver, Cheren (1997), Eloy Martínez (2009), Seoane (1992), Binder et al (2015) y Pittaluga (2006).
} 
Enrique Gorriarán Merlo y Domingo Menna), las FAR (Roberto Quieto y Carlos Osatinsky) y Montoneros (Fernando Vaca Narvaja). También estaba prisionero Agustín Tosco, el máximo dirigente del sindicato de Luz y Fuerza de la provincia de Córdoba que había tenido un rol central en el estallido popular antes mencionado.

No obstante las diferentes concepciones acerca del rol que jugaría Juan Domingo Perón, exiliado en la España franquista, en el proceso revolucionario (para Montoneros, aquél lo encabezaría, para el ERP, por el contrario, era la "última tabla de salvación" (de Santis, 1998: 122) del capitalismo argentino), la fuga del penal chubutense fue organizada en conjunto por las tres organizaciones mencionadas e incluyó apoyo externo e interno. Respecto al primero, varias camionetas y autos particulares para recoger a los fugados y trasladarlos al aeropuerto de Trelew, distante a unos 20 kilómetros del penal y el secuestro de un avión de la compañía Austral, proveniente de Bahía Blanca, por "falsos" pasajeros armados que lo habían abordado en Buenos Aires. ${ }^{9}$ El apoyo interno fue obtenido sobornando a un guardia que facilitó armas que permitieron la toma del establecimiento.

Como es sabido, algunas desinteligencias trastocaron el plan original milimétricamente diseñado: el asesinato de un guardiacárcel que intentó detener a los fugados y la huida de los vehículos - al escuchar las detonacionesque debían trasladar a los guerrilleros al aeropuerto. Solo un auto logró su cometido: en el viejo Ford Falcón conducido por Carlos Goldenberg se montaron los seis líderes guerrilleros mencionados que lograron llegar a abordar el avión -Vuelo 811 de Austral-, ya secuestrado por tres guerrilleros.

Santucho intimó al piloto a que los trasladara a La Habana, pero este indicó, con tino, que el avión (BAC 111), no tenía la autonomía suficiente para realizar ese vuelo. Luego de algunos intercambios de palabras entre los guerrilleros, y en un clima de extrema tensión por el resto de los compañeros que no llegaban, se decidió emprender viaje a Chile. Cierta simpatía con el proceso político encabezado por Salvador Allende y los vínculos existentes con la guerrilla chilena del MIR (Movimiento de Izquierda Revolucionaria) fueron la causa probable de la estrategia elegida.

Lo que ocurrió a posteriori es bien conocido: el resto de los fugados, diecinueve guerrilleros, lograron llegar en remises al aeropuerto, pero ya era tarde. ${ }^{10}$ El avión había despegado y las Fuerzas Armadas, alertadas de lo

\footnotetext{
${ }^{9}$ En el marco de esta investigación, entrevistamos a Eduardo Ford, piloto del avión que condujo a los guerrilleros fugados a Chile. Ford nos indicó que el itinerario habitual del avión era: Buenos Aires-Bahía Blanca-Trelew-Comodoro Rivadavia y regreso a Buenos Aires.

${ }^{10}$ Los guerrilleros que lograron fugar aterrizaron horas después en el aeropuerto de Pudahuel donde fueron recibidos por el Director General de Investigaciones (interino) Arsenio Poupin. Dirigidos por Santucho, parlamentan durante tres horas y solicitaron asilo político. Al otro día, el avión secuestrado regresó a la Argentina.
} 
sucedido, cerraron el espacio aéreo. Los guerrilleros tomaron el aeropuerto, llamaron a los medios de comunicación y a un juez para que constatara su perfecto estado de salud y se rindieron.

Sin embargo, no fueron llevados nuevamente al penal, que estaba convulsionado por la fuga y tomado por el resto de los penados, sino a la Base de la Marina Almirante Zar, en Trelew. Allí, una semana después, en la madrugada del 22 de agosto, fueron sacados de sus celdas y fusilados. De los 19 guerrilleros, en la confusión de gritos, tiros y sangre, 3 sobrevivieron.

La noticia conmocionó a todo el arco político y fue noticia internacional. El gobierno fue dando varias absurdas versiones sobre los fusilamientos, que con el paso de los días se esclarecerían a partir de los testimonios de testigos y en especial de los sobrevivientes. Las 62 Organizaciones Peronistas e incluso la Unión Cívica Radical -el Ministro del Interior Arturo Mor Roig había sido diputado radical- condenaron los sucesos y pidieron el esclarecimiento de los hechos. Ya en la madrugada del 16 de agosto, Mor Roig recibió a los periodistas en la Casa Rosada (Esta madrugada, 1972). Las versiones oficiales eran francamente encontradas, y como se probaría, falsas.

Todo el arco político repudió el accionar de las Fuerzas Armadas: el Frente Cívico de Liberación Nacional, el Movimiento Peronista, las 62 Organizaciones, la Juventud Peronista, el Partido Popular Cristiano, el ex presidente Arturo Frondizi, del Movimiento de Integración y Desarrollo (MID), la Unión Cívica Radical, etc (Inquietud de los radicales, 1972: 5). También la Franja Morada, que representaba a sectores importantes del estudiantado, repudió la masacre y afirmó que "está próximo el triunfo de la soberanía nacional y la derrota del privilegio nacional e internacional". Asimismo, pequeñas agrupaciones de derecha e izquierda repudiaron lo sucedido. Por ejemplo, el Movimiento Unión y Reorganización Nacional presidido por Ernesto Sanmartino afirmó que "su condena al terrorismo alentado desde el exterior no significa solidaridad ni tolerancia con los regímenes dictatoriales" y el Frente de Izquierda Popular, de Jorge Abelardo Ramos, comparó estos hechos con el fusilamiento de Manuel Dorrego en 1828, afirmando que "lo ocurrido en Trelew es consecuencia de la proscripción de las mayorías por las clases explotadoras". ${ }^{11}$

Mientras Lanusse asumía la responsabilidad política de la masacre, Perón ordenó que los guerrilleros fusilados fuesen velados en la sede del Partido Justicialista de la Capital Federal. Así que, que Ana María Villarreal -esposa de Santucho, asesinada en Trelew (embarazada)-, María Angélica Sabelli y Eduardo Capello ${ }^{12}$ fuesen velados en la casa partidaria del peronismo es el

\footnotetext{
${ }^{11}$ Las referencias fueron tomadas de los diarios La Nación y Clarín de los días 24 a 27 de agosto de 1972.

${ }^{12} \mathrm{El}$ resto de los asesinados fueron trasladados a sus provincias de origen.
} 
símbolo de una época en que la dictadura militar era severamente cuestionada y las organizaciones armadas -incluso las críticas al peronismo- contaban con apoyo popular. La dictadura no cesó en su demostración de fuerza. Hubo un incesante desfile de gente durante toda la noche mientras se velaban los cuerpos de los dos primeros. Estaban allí los sacerdotes Carbone, Mugica y Monseñor Podestá. El féretro de Villarreal llegó a la mañana siguiente. El general Tomás Sánchez de Bustamante jefe del Cuerpo del Ejército I, ordenó a la guardia de Infantería de la Policía Federal "dispersar" (Cheren, 1997: 118) a los presentes. La sede del PJ fue asediada con caballos, perros, palos, granadas de gas lacrimógeno y hasta tanques. Trasladaron violentamente los tres féretros al cementerio, pero ni aun con ese despliegue represivo lograron impedir las manifestaciones en distintos puntos de la ciudad por un accionar que no registraba antecedente (Cheren, 1997: 118).

Como veremos en el siguiente apartado con más detenimiento, la perpetuación de la masacre influyó poderosamente en la decisión de Salvador Allende de no aceptar la extradición de los diez guerrilleros solicitada por el gobierno argentino y otorgarles un salvoconducto y un avión para que se dirigiesen a la Cuba revolucionaria.

Analizaremos en el próximo apartado las comunicaciones emitidas por la Cancillería Argentina y el consulado en Santiago de Chile.

\section{Las negociaciones diplomáticas entre Argentina y Chile: ¿extradición o autodeterminación?}

En tal complejo escenario político de ambos países y del continente, la llegada de los evadidos a Chile el día 15 de agosto, conmocionó a los distintos sectores internos de ese país. Generó fuertes presiones al gobierno de Allende tanto desde la izquierda como desde la derecha conspirativa. Por los primeros, fue considerada un triunfo, e insistirían para que su gobierno colaborara con el traslado de los fugados hacia un destino de asilo. Los segundos se encontraban en plena estrategia golpista contra un gobierno decidido a avanzar hacia el socialismo por la vía democrática.

Lo cierto es que la situación puso en tensión las relaciones bilaterales que hemos descripto y atentaba contra la política exterior promovida por Lanusse. Ello, en consecuencia, también profundizaba las internas en esa disputada dictadura. En el mes de julio corrieron rumores de renuncia por parte de Lanusse, que probablemente provenían de las presiones de la Fuerza Aérea y su Comandante, el General Rey. La crítica de estos sectores se relacionaba con dos cuestiones: las conversaciones secretas con Perón, y el rol de la Fuerza Aérea en el gobierno militar. Tanto Rey como López Aufranc, descripto por los documentos de la CIA como el "poderoso Jefe del III Cuerpo en Córdoba" protestaban públicamente por la falta de conocimiento del contenido de la 
conversación entre Perón y el emisario privado del presidente de facto (Central Intelligence Bulletin, 7 de julio de 1972: 6). En efecto, se trataba de una dictadura rechazada por los sectores democráticos de la población, por las juventudes organizadas y, por otra parte, presionada por el antiperonismo más duro y su temor al regreso del líder proscripto.

El primer contacto entre los mandatarios fue telefónico. Lanusse llamó a Allende esa misma noche (Lanusse conversó, 1972). El día 16 de agosto la Embajada Argentina en Santiago solicitó al Ministerio de Relaciones Exteriores de Chile la detención preventiva, a los fines de la extradición, de aquellos individuos procesados por delitos comunes, algunos de ellos evadidos de una cárcel argentina, según el procedimiento previsto en la VII Conferencia Internacional Americana realizada en Montevideo en 1933. A pedido del gobierno de Chile, el gobierno argentino se comprometió a presentar los antecedentes necesarios para que la justicia chilena se pronunciara.

El reporte diario confeccionado para el presidente Nixon por la CIA del 17 de agosto de 1972, informa la llegada del avión secuestrado, y relata la difícil situación para Allende:

"Allende quisiera mantener las cordiales relaciones con el presidente argentino Lanusse, pero Chile tiene una larga tradición de ofrecer refugio a disidentes sudamericanos de toda clase. Y extraditar a los extremistas provocará duras reacciones por parte de muchos miembros de su gobierno (...) En casos similares del pasado, Chile denegó el asilo formal, pero permitió a los fugitivos continuar su camino hacia otros países que los aceptaran. Cuba podría ser la opción de este grupo." (The President's Daily Brief, 17 de agosto de 1972: 5)

En efecto, poco tiempo atrás Chile había demostrado ser consecuente respecto de los pedidos de asilo político. Hacia 1971 se solicitó a ese gobierno mediación en el caso de los Tupamaros y la negativa fue contundente alegando la vigencia de la no intervención. El 18 de agosto, el diario Clarín publica una entrevista realizada al presidente Allende donde este aclara su posición y afirma:

“...en primer lugar, Chile ha firmado un convenio, como la mayoría de los países del mundo, en el caso de Chile ratificado por el Congreso, que sanciona la piratería aérea y que obliga a poner a disposición de la justicia a quienes han cometido ese delito. El caso extraordinario de Chile es que habiendo ratificado este convenio no establece una pena y por lo tanto no se les puede aplicar la pena que establece el código penal para otros delitos. Por una parte [...] será la justicia la que debe determinar. Por otra, si el gobierno argentino solicita la 
extradición será también la justicia la que determinará y ellos tienen todos los derechos para ser defendidos ante el tribunal y tener los abogados que deseen. $\mathrm{Y}$ ese tribunal debe determinar si son delitos políticos o comunes." (Reportaje, 18 de agosto de 1972: 13).

Fue el encargado de negocios de la República Argentina en Chile, Gustavo Figueroa, quien informaría constantemente a la cancillería argentina de las repercusiones de la fuga en el país transandino. La primera de las comunicaciones remitía los principales recortes periodísticos de la prensa chilena $^{13}$ y el mismo día -fecha de los fusilamientos- encontramos otra carta reservada también de Figueroa al canciller argentino. El escrito transmite la posición del canciller Clodomiro Almeyda, explicando que se trata de un funcionario proveniente de la "línea dura" del socialismo. Allí reproduce lo que dijera el canciller chileno en una entrevista periodística,

"Almeyda explicó que antes de las funciones que ejerce actualmente, había sido Secretario General del Partido Socialista en relaciones internacionales y que en esa calidad, se desempeñaba como 'jefe de relaciones de un partido revolucionario'. Aclaró, en otras palabras, que había tenido que adaptar su posición a la actividad diplomática de las relaciones internacionales en que la 'transacción es lo más frecuente', como medio de evitar conflictos. Señaló que dentro de este panorama, a su entender, Chile no aparecía en posición de agresor o de víctima, sino de 'sujeto activo', ya que un país en transición al socialismo, genera conflictos tanto en el orden interno cuanto en el externo. Nosotros, agregó, 'estamos por la negociación'."14

Otra de las comunicaciones entre ambos funcionarios informa de la presión de la Unión Socialista Popular (USP) ${ }^{15}$ sobre Allende. Figueroa sostiene al respecto:

"En ocasión de este conocido episodio, el grupo político a que me vengo refiriendo criticó duramente al Gobierno por su actitud 'oportunista y vacilante, que no solo ha sido inconsecuente con nuestra tradición de prestar asilo, sino también con la conducta que debe observar un Gobierno

\footnotetext{
${ }^{13}$ Carta de Figueroa a Mac Loughlin (A), 22 de agosto de 1972 [AMRECA] Caja AH 0040.

${ }^{14}$ Carta de Figueroa a Mc. Loughlin (B), 22 de agosto 1972, [AMRECA] Caja AH 0040.

${ }^{15}$ La Unión Popular Socialista, partido fundado en 1967, apoyó críticamente al gobierno de Allende. No tuvo participación ninguna en la parte administrativa del gobierno, pero sí sus militantes participaban activamente en todos los frentes sociales
} 
revolucionario'. Al referirse a los secuestradores, los define como 'dirigentes políticos arbitrariamente privados de libertad por las autoridades del Gobierno de Allende, que pretende 'endosar las responsabilidades del problema a los Tribunales de Justicia a sabiendas que con ello se les asegura una suerte oscura'. Acusa al oficialismo de falto de consecuencia con los principios revolucionarios. Al referirse a nuestro país, lo hace con estas palabras: lo dirige una dictadura militar 'que ha ejercido presión sobre el Gobierno chileno [...] y que cuando un Gobierno es verdaderamente revolucionario, puede y debe negarse al chantaje de una dictadura militar.' La USP exige se otorgue, sin más dilaciones, asilo político a los secuestradores." 16

Las opciones que las fuerzas políticas chilenas barajaban eran dos: o bien iniciar un proceso judicial en Chile por haber ingresado al país sin documentación, $\mathrm{u}$ otorgar un salvoconducto hacia otro país. De acuerdo con prensa del período, la coalición de la Unión Popular acordaba en su conjunto con evitar la extradición y resolver legalmente a través de una decisión de la Corte Suprema. Por otro lado, el MIR y el ala más radical del Partidos Socialista se posicionaron fuertemente a través de protestas, a favor de otorgar asilo o salvoconducto, presionando fuertemente a Allende en esa dirección (Negarían el pedido de extradición, 1972: 4). Recordemos que se trata de un período de recrudecimiento de las disputas dentro de la Unión Popular entre el Partido Comunista Chileno y el ala más radicalizada del Partido Socialista, a las que se sumaban las presiones del MIR, que desembocarían en una importante crisis en el mes de octubre. La primera de esas organizaciones se mostraba más proclive a políticas "moderadas" y en el marco de la legalidad, para afianzar los logros obtenidos por el gobierno desde 1970 (Corvalán, 1972: s/p).

Abogados representantes de los fugados -Mario Amaya, Gustavo Roca y Eduardo Luis Duhalde- viajaron a Chile a reunirse con el presidente Allende en el Palacio de la Moneda, el día 22 de agosto. Mientras tanto, se producían los desgarradores hechos de la masacre perpetrada en Almirante Zar. En el mismo instante en que debía tomarse una decisión, los planes golpistas crecían entre la oposición chilena. Da cuenta de ello el informe diario de la CIA al presidente de los Estados Unidos, fechado el 23 de agosto, que indica que muchos líderes militares estaban conspirando contra el presidente (CIA, The President's, 1972: $5)$.

Del otro lado de la cordillera, Lanusse recrudecía la represión, ya habiendo perdido esperanzas de conformar un Gran Acuerdo Nacional que lo llevara como candidato a la presidencia.

\footnotetext{
16 Carta de Figueroa a MC Loughlin, 23 de agosto de 1972, [AMRECA], Caja AH0040. Las cursivas son nuestras.
} 
Tal como relata Duhalde, los abogados fueron recibidos el día 25 de agosto -agrega que los del Partido Comunista Argentino decidieron no viajar-, en una reunión a la que asistieron todos los ministros del gobierno de Allende, y cada uno expondría su tesis de "extradición o encarcelamiento". Según él, Almeyda fue quien presentó más claramente la dificultad que implicaba negar la extradición, no solamente en términos legales sino respecto de las relaciones internacionales con la Argentina y con otros países de la región como Bolivia y Brasil (Seoane, 1992). Algunos barajaban la opción de mantenerlos presos en alguna dependencia que no fuera directamente una cárcel. El único que firmemente defendía el asilo fue del secretario del Tesoro, Antonio Novoa Montreal. Duhalde sostiene que, en ese momento, Allende afirmó: "Chile no es un portaviones para que se lo use como base de operaciones. Chile es un país capitalista con un gobierno socialista y nuestra situación es realmente difícil [...] Pero éste es un gobierno socialista, mierda, así que esta noche se van para La Habana" (Seoane, 1992: 247).

La decisión de conceder asilo político a los evadidos fue comunicada formalmente en una carta del canciller Almeyda a Figueroa. Allí se argumenta que:

“Del estudio de los antecedentes emanados de las autoridades argentinas y de los recogidos por las de nuestro país, aparecen datos que permiten conseguir dudas razonables de que los delitos que se atribuyen a las personas afectadas puedan ser calificados de comunes, y por el contrario, el Gobierno aprecia la existencia de hechos constitutivos de delitos políticos de otros conexos con los mismos." (Carta de Almeyda a Figueroa, transcripta en Cheren, 1997: 233)

Y que, por lo tanto, y considerando la "tradición inalterable" que Chile ha mantenido respecto del derecho de asilo, "este Ministerio ha acordado conceder asilo político a las personas citadas" (Carta de Almeyda a Figueroa, transcripta en Cheren, 1997: 233). A ello, se agrega la aclaración de que el Gobierno de Chile "ha resuelto que estos asilados políticos abandonen el territorio nacional dentro del más breve plazo" (Carta de Almeyda a Figueroa, transcripta en Cheren, 1997: 233)

Otro de los informes diarios de inteligencia entregados por la CIA al presidente Nixon, con fecha 26 de agosto, afirma que Lanusse confirmaba las elecciones presidenciales para el mes de marzo de 1973, con la exclusión de Perón, ya que no se había presentado en la Argentina antes del día 25, como exigía la legislación impuesta por el propio dictador. Al mismo tiempo el informe refiere al caso de Trelew, sosteniendo que Lanusse defendía y mantenía su determinación respecto la acción militar y el fusilamiento de dieciséis de los diecinueve fugados, a pesar de las manifestaciones públicas contrarias. Finaliza 
diciendo: "En la escena internacional, las buenas relaciones entre Argentina y Chile, cuidadosamente alimentadas por ambos presidentes pueden estar en riesgo" (The President's, 1972: 7).

La respuesta del gobierno argentino llegó el día 27, con una firme nota de protesta del Ministerio de Relaciones Exteriores y Culto dirigida al Embajador de Chile Ramón Huidobro Domínguez. Allí el canciller afirma: "ha causado profundo desagrado a mi gobierno este proceder de V.E. pues en la historia de nuestras relaciones siempre nuestros países se habían atenido estrictamente al cumplimiento de tratados vigentes" (Carta de Mc Loughlin a Huidobro Domínguez, en Cheren, 1997: 237). La acusación argentina giraba en torno a la falta de cumplimiento de la legalidad de los tratados internacionales, en particular la Convención de Extradición de 1933 y expresaba su "más severa y formal protesta" (citado en Cheren, 1997: 233). ${ }^{17}$ Una extensa respuesta de Almeyda se haría esperar varios días, donde se justificaba la posición chilena, argumentado que se encontraba acorde a derecho (Cheren, 1997: 243).

Entre los documentos diplomáticos del Archivo del Ministerio de Relaciones Exteriores y Culto de la Argentina [AMRECA], se encuentra también una carta de Figueroa al canciller Mc Loughlin, fechada el 28 de agosto, cuyo asunto es "Evaluar decisión Chile caso secuestradores del avión de la compañía Austral". Allí expresa sus impresiones sobre el problema del siguiente modo:

“Chile se encontró abocado a resolver un caso inesperado y para ello debió arbitrar una solución de emergencia; por lo tanto, no midió el alcance real de las responsabilidades que asumía al aceptar en su territorio la presencia -sin duda, poca grata, al menos desde el punto de vista de las relaciones bilaterales- de diez sujetos penados por la justicia argentina por la comisión de diversos delitos. Es decir, entonces, que si el factor sorpresa no hubiese existido habría tenido tiempo de sopesar pros y contras y por ende, tal vez habría optado por una decisión tendiente a evitar la permanencia de los terroristas en su territorio nacional." 18

La posición de Figueroa, profundamente crítica de la ideología de Almeyda, en este sentido es más bien pragmática, y justificatoria de la decisión de Allende. El funcionario pareciera estar en línea con no fracturar aún más el vínculo bilateral. En su carta continúa afirmando:

“Desde el momento que dicha permanencia quedó formalizada, la suerte de las autoridades chilenas estaba echada y se vieron

\footnotetext{
17 Carta del Ministerio de Relaciones Exterior de la Nación Argentina, al Sr. Embajador de Chile en Buenos Aires, Dr. Ramón Huidobro Domínguez, Buenos Aires, 27 de agosto de 1972.

18 Carta de Figueroa a Mc Loghlin, 28 de agosto de 1972, [AMRECA], Caja AH 0040.
} 
obligadas a seleccionar entre 'frente interno' o respeto por la línea de amistad que nuestro país comenzó por trazarle al pronunciarse el jefe del estado argentino, por derribar las evidentes 'barreras o fronteras ideológicas' que separan a las dos naciones." 19

Aquí hace una referencia concreta a la política exterior de Lanusse y a la nueva orientación en las relaciones internacionales. Pondera como causa de la decisión, los condicionantes internos. La carta relata la presión de "personalidad de distintos partidos de combinación oficialista", que se acercaron al Departamento de Investigaciones en solidaridad con los "evadidos", así como la movilización en las calles en apoyo a "revolucionarios perseguidos por una dictadura militar" (Figueroa cita en este sentido las palabras de miristas y socialistas). Tal como describen los documentos y reportes de los Estados Unidos, Chile se encontraba en una frágil situación política, con planes de golpe de estado en marcha, que serían apoyados por la potencia del norte.

Uno de los documentos del Departamento de Estado de fecha 30 de agosto, relata que la cuestión de la fuga de Trelew se da en un contexto de "deterioro de la situación económica y política en Chile", donde "pueden esperarse" incidentes de grupos de derecha y de izquierda. Refiere directamente a la creciente polarización entre el gobierno y las fuerzas armadas y sostiene:

"En medio de estos eventos, el caso de los secuestradores argentinos contribuyó a complicar las cosas para el gobierno y alteró la distensión cuidadosamente elaborada del Presidente Allende con Argentina. Hasta el momento, la reacción argentina se ha limitado al retiro de su embajador, pero si el Presidente Lanusse decide sobre una represalia más fuerte, como la reducción de los envíos de carne vacuna a Chile, los problemas económicos de Allende se agravarán aún más. Por otro lado, si la reacción argentina se vuelve demasiado extrema, ofrecerá a Allende la oportunidad de convertir el problema en un elemento de carácter nacional y patriótico y distraer al público de sus problemas económicos."20 (Memorandum from Shckaley to Helms, 1972: 809)

\footnotetext{
${ }^{19}$ Carta de Figueroa a Mc Louglin, 28 de agosto de 1972, [AMRECA], Caja AH 0040.

${ }^{20}$ Memorandum from the Chief of the Western Hemisphere Division of the Directorate of Plans, Central Intelligence Agency (Shackley) to Director of Central Intelligence Helms, Subjetct: "The Deteriorating Situation in Chile", Santiago, August 30, 1972. Foreign Relation of de United States (FRUS), p. 809.
} 
Puntualmente respecto de las intenciones golpistas de sectores de "derecha", y de los liderados por el general Alfredo Canales, el mismo documento da cuenta de la compleja situación política:

“Los grupos militantes de derecha, apoyados por intereses comerciales, ahora están comenzando a tratar de exacerbar las tensiones para provocar que los militares entren en acción. Las fuerzas de izquierda, lideradas por el Movimiento de la Izquierda Revolucionaria (MIR), sin duda enfrentarán el desafío de la derecha y se producirán más incidentes en las calles de la ciudad y en las zonas rurales. Aunque el general Alfredo Canales tiene un golpe de estado organizado entre los oficiales militares clave de acuerdo con informes anteriores, no ha dado ninguna señal durante el malestar actual de sentir que el momento es el momento adecuado para él." ${ }^{21}$

En este sentido, volvemos a la citada carta de Figueroa para comprender cabalmente la siguiente conclusión:

“...no le fue posible al jefe del estado trasladar el tratamiento del caso a la Justicia. La presión interna lo superó. Como consecuencia de lo anterior, debió derivarlo al Ministerio del Interior, o sea, al Ministerio político, siéndole inevitable tratarlo como un problema de tal índole. Esto sucede pese a que Allende no ignora que la actitud de nuestro país, en adelante, ha de sufrir variaciones -formales o de fondo, pero variaciones al fin-, con lo cual las relaciones entre Argentina y Chile se verán enervadas, lo que hace muy poco favor a la Unidad Popular, que hasta este momento ha podido presentarse internacionalmente como manteniendo entendimientos cordiales con un Gobierno limítrofe de ideología muy diferente de la suya, ergo, primer aval de la 'vía chilena'." (Carta de Figueroa a Mc Loughlin, 28 de agosto de 1972, [AMRECA])

El punto de inflexión en las relaciones bilaterales y sus posibles consecuencias, aparecen abordadas en un reporte diario de la CIA a Nixon del 30 de agosto, que refleja la protesta del gobierno argentino del siguiente modo: “Buenos Aires expresó su 'profundo descontento' a la decisión del presidente chileno Allende de enviar a Cuba a los terroristas que secuestraron un avión hacia Santiago hace dos semanas, y no devolverlos a la Argentina" (Central Intelligence Bulletin, 1972: 8). El documento sostiene que según el Ministro de

\footnotetext{
${ }^{21}$ Memorandum from the Chief of the Western Hemisphere Division of the Directorate of Plans, Central Intelligence Agency (Shackley) to Director of Central Intelligence Helms, Subjetct: "The Deteriorating Situation in Chile", Santiago, August 30, 1972. Foreign Relation of de United States (FRUS), p. 810.
} 
Relaciones Exteriores de la Argentina su gobierno tiene la intención de “ajustar las tuercas" con Chile, amenazando con sanciones económicas:

"Argentina es un importante abastecedor de carne y grano hacia Chile [...] No pareciera probable que la Argentina vaya tan lejos, dándole la espalda a un importante socio comercial y con quien comparte muchos proyectos bilaterales beneficiosos para ambos países; pero la política de abandono de las barreras ideológicas de Lanusse sufrirá un gran revés." (Central Intelligence Bulletin, 1972: 8).

\section{La repercusión en la prensa latinoamericana: Colombia y Cuba}

El tratamiento de la fuga de Rawson y la masacre de Trelew en la prensa colombiana -a la que hemos accedido a través de la documentación de la cancillería argentina- pivoteó sobre varios asuntos: 1) El modo en que la decisión de Salvador Allende de no extraditar a los diez guerrilleros impactaría en las excelentes relaciones Argentina-Chile, entre un "ideólogo marxista y un general de carrera", 22 que podía conducir al enfriamiento e incluso a la ruptura de relaciones entre ambas naciones; ${ }^{23}$ 2) Las tensiones internas a las que estaba sometido Allende, en especial por el Partido Socialista y el Movimiento de Izquierda Revolucionaria, reacios a entregar a los guerrilleros a la Corte Suprema y a su posterior extradición; ${ }^{24}$ 3) El modo en que la masacre de los 19

22 "Las tensiones argentino-chilenas." El Espectador. 28 de agosto de 1972, p.5.

${ }^{23}$ Véase, "Tensión chileno-argentina" en El Tiempo; "Enfriamiento" y "Argentina rompería relaciones con Chile" en El Siglo, ambas del 28 de agosto de 1972. También, el mismo día, Julio Argain -corresponsal en Buenos Aires-, publicó en El Colombiano un artículo titulado "Los amigos terroristas", en que criticaba ferozmente a los países que recibían guerrilleros (Cuba, México, Argelia, Rusia, etc.). Respecto a la situación de los fugados argentinos señaló que "...la extradición de los delincuentes solicitada por Argentina reviste trascendencia especialísima para el mandatario chileno. Puede afirmarse que de ello depende el futuro de las relaciones entre ambos países limítrofes. Argentina se ve perturbada en estos momentos por una ola de terrorismo político desatada por grupos que por este medio pretenden el incumplimiento de las elecciones proyectadas para marzo de 1973, destinadas al retorno de la normalidad institucional. Si Chile da protección a quienes cometen delitos comunes extremos para la consecución de tales fines, por fuerza el gobierno de Buenos Aires tomará nota de su actitud. En la capital chilena se suceden las manifestaciones públicas en las que la izquierda revolucionaria exige a Allende la inmediata libertad de los delincuentes argentinos, justificando el asesinato de un agente uniformado de seguridad y la piratería aérea. Como se ve, los 'amigos' terroristas no son demasiado deseables. Las actuales relaciones argentino-chilenas son buenas, a pesar de las opuestas ideologías de sus gobiernos y así les conviene mantenerlas a ambas partes. La que infrinja tal situación cargará con responsabilidad y consecuencias de insospechable alcance" [AMRECA], caja AH/0118.

${ }^{24}$ Algunos periodistas afirmaban que más allá de las presiones de los sectores de izquierda del gobierno chileno, ya Allende previamente había actuado defendiendo a guerrilleros. Así, en una nota de Julio Argain en El Colombiano, titulada "El llano no es el gobierno", este afirmaba 
guerrilleros en la base Almirante Zar inclinó decididamente la balanza para otorgarles el salvoconducto y enviarlos a La Habana (Matanza en Rawson, 1972); 4) La decisión de Allende que desconoció las normas jurídicas internacionales iba a deteriorar la posición de Chile y demostraba la victoria del "extremismo" y, por último, 5) Los sucesos de Trelew mostraban fisuras al interior de las Fuerzas Armadas argentinas divisándose tres sectores: uno aperturista hacia el proceso electoral, encabezado por Lanusse, una fracción en la Fuerza Aérea, partidaria de establecer un régimen de izquierda, al estilo peruano y un sector más inclinado por el modelo brasileño, pronorteamericano, que restringiese las libertades sindicales, otorgando "amplias garantías a inversionistas extranjeros" (Divergencias, 1972).

Como señalamos, la masacre de Trelew aceleró la decisión del gobierno chileno de no ceder a las presiones de la dictadura argentino para extraditar a los diez guerrilleros e inició el operativo para otorgarles un salvoconducto y que se dirigieran a Cuba. Quedará para futuras investigaciones el análisis de las negociaciones entre las cancillerías chilena y cubana acerca de la urticante

que “...en 1968 el actual mandatario chileno marxista doctor Salvador Allende, era presidente del Senado. Llegaron entonces a su país los guerrilleros bolivianos y cubanos que huían luego de la fracasada subversión armada encabezada por Ernesto Guevara. El señor Allende defendió ardorosamente a los insurrectos del altiplano, hizo causa común con ellos y los cubrió con la influencia de su inmunidad parlamentaria. Desde luego, con la adhesión indirecta del entonces presidente de Chile, Eduardo Frei, preocupado de buscar simpatías entre los marxistas para el afianzamiento y continuación en el poder de su partido aparentemente demócrata-cristiano. No vaciló el señor Allende en ir tan lejos cuanto podía en esa ocasión. Ya era por la cuarta vez consecutiva candidato presidencial en potencia de la extrema izquierda y accionaba con todos los medios a su alcance. Sacó personalmente de Chile a los guerrilleros en fuga para que eludieran la justicia y los acompañó en su viaje a la lejana Tahití -isla de Polinesia en Oceanía, al margen de toda posibilidad de extradición- y los revolucionarios del mundo quedaron admirados y conmovidos y se volcaron férreamente unidos en torno del líder que hasta exponía su integridad personal en defensa de sus ideales marxistas. Y hubo entonces algo más que nadie recuerda en este momento y que fue que el doctor Allende calificó a los guerrilleros terroristas de 'padres de la patria'. Es natural que hoy le resulte difícil encarcelar y entregar a la justicia a estos émulos argentinos de aquellos, y a todos los cuales, según su concepto, están al mismo nivel de Washington, el precursor Miranda, San Martín, Bolívar, Sucre, O' Higgins y cuantos próceres más. Llega este deplorable agosto de 1972 para el presidente Allende y se ve sorprendido por el sorpresivo arribo a su tierra de los diez guerrilleros argentinos. Seis de estos participantes en el asesinato de un guardia uniformado al copar la cárcel de la cual escapan, secuestran un avión que utilizan en su huida; acto de piratería aérea, delito que Chile reconoce y se compromete a castigar en un convenio internacional. Se plantea entonces un conflicto grave en el seno del gobierno izquierdista de Chile que preside Allende. Según los principios socialistas que sostiene el régimen, no son delincuentes comunes. El propio señor Allende lo estableció en el caso similar de los bolivianos y cubanos que él patrocinó en 1968 y así lo sostuvo desde el llano en su campaña electoral. Pero el orador de la plaza pública no es el estadista que ocupa la presidencia de un país y ambas actitudes y conceptos están separados por la honda brecha que media entre el populachero irresponsable que puede especular con la emoción de sus seguidores y el ciudadano con deberes que no pueden ser olvidados y comprometer el prestigio y los sagrados intereses de la nación" [AMRECA], caja AH/0118. 
cuestión de los guerrilleros argentinos, no obstante, es sabido que Allende y Fidel Castro tenían buenos vínculos (este había realizado una visita al país trasandino en 1971).

¿Dónde colocó el acento la prensa cubana? Apenas concretada la fuga, el diario Granma informó que se conocía la identidad de los diez guerrilleros que habían arribado a Chile; ${ }^{25}$ que estos habían accedido someterse a la jurisdicción de las leyes chilenas y los convenios internacionales y que la dictadura argentina solicitaría la extradición.

Una semana después, ya conocida la masacre ocurrida en Trelew, a diferencia de la prensa colombiana que reprodujo la versión de la dictadura argentina que los guerrilleros habían intentado fugarse, el Granma responsabilizó al régimen fascista de Lanusse por lo sucedido. También hizo hincapié en el hondo malestar existente en las provincias, en las grandes manifestaciones reprimidas y elogiaba al sindicalismo combativo de Córdoba (Eleváse a 16, 1972; Setenta detenidos, 1972). ${ }^{26}$ Por último, daba cuenta de la bárbara actitud del Jefe de la Policía Federal, Alberto Villar, que secuestró los féretros de los guerrilleros que estaban siendo velados en la sede del Partido Justicialista (Secuestran, 1972). ${ }^{27}$

El día 28 de agosto, el Granma informó acerca de la llegada a Cuba de los revolucionarios argentinos: al aterrizar en La Habana estos fueron recibidos por Adalberto Quintana, director del Instituto Cubano de Amistad con los Pueblos e improvisaron una conferencia de prensa en el aeropuerto. En esa ocasión, Mario Roberto Santucho señaló la alegría por estar allí, analizó la importancia de la fuga realizada en conjunto por las tres organizaciones (pese a sus diferencias ideológicas y sobre el rol del peronismo) y responsabilizó directamente a Lanusse por la masacre de los 16 guerrilleros (En Cuba, 1972).

Al día siguiente, el periódico cubano publicó una larga nota de Carlos Altamirano, Secretario General del Partido Socialista Chileno en la que

\footnotetext{
${ }^{25}$ Con algunas erratas, el Granma informaba que los fugados eran: "1) Carlos Goldenberg Fernández, 19 años, soltero, estudiante de Agronomía; 2) Roberto Jorge Quieto Arganaras, 34, casado, abogado; 3) Domingo Mena Ferreyra, 25, soltero, estudiante de Medicina; 4) Víctor José Fernández Palmeira (sic), español, soltero, 27 años, estudiante de Medicina; 5) Ana Wiessen Miklasky, casada, profesora, 23 años; 6) Fernando Bacca Narbaja (sic), 24 años, casado, estudiante de Ingeniería Química; 7) Enrique Arnoldo Gorriarán Merlo, 30 años, casado, perito comercial; 8) Alejandro Enrique Ferreyra Beltrán, 23 años, casado, estudiante de Medicina; 9) Marcos Osatinsky Schlosberg, 38 años, casado, empleado y 10) Mario Roberto Santuccio Suárez (sic), 36 años, casado, contador" (Identifican, 1972). Agradecemos al historiador y abogado cubano Adrián Jesús Cabrera Bibiloni la remisión de las fuentes utilizadas en este apartado.

${ }^{26}$ Similar enfoque puede verse en el diario Juventud Revolucionaria.

27 Unos días después, la prensa cubana señaló que los familiares de los fusilados en Trelew descreían de la versión oficial sobre una supuesta fuga y que la Asociación Internacional de Juristas Democráticos -con sede en Bruselas- había denunciado al gobierno argentino. Véase, "Denuncian el salvajismo del asesinato de Trelew", en Granma, 6 de septiembre de 1972, p.10.
} 
exhortaba a la solidaridad de todos los revolucionarios de América Latina. Asimismo, definía el asilo otorgado a los guerrilleros argentinos como una consecuencia de la política contra la opresión practicada por el gobierno chileno. Concluía afirmando, en tono desafiante que no "sigan jugando con fuego porque a la violencia reaccionaria opondrán la violencia revolucionaria" (Granma, 29 de agosto de 1972: 3).

\section{Conclusiones}

El aterrizaje del avión secuestrado el 15 de agosto por los fugados del penal de Rawson pondría en jaque las relaciones bilaterales entre Argentina y Chile, en un contexto donde habían alcanzado un alto nivel de entendimiento. Los documentos de los Estados Unidos son los que mejor demuestran esa dificultad y la tensión bilateral que generó el conflicto.

La compleja situación interna en ambos países se expresó también en este plano. Allende se vio en la difícil situación de erosionar el vínculo con Lanusse o dañar su imagen frente a la izquierda chilena y latinoamericana. La dictadura argentina mostraba su costado más real: la represión feroz se imponía más allá de las apelaciones al "pluralismo ideológico", que parecía ser más bien una estrategia económica (y no política) en el contexto de un continente disputado en el contexto de la Guerra Fría y que se radicalizaba (Bologna, 1977: 195). El peronismo, las organizaciones sociales de izquierda, el sindicalismo, continuarían pujando por la apertura a las elecciones, y la violencia se recrudecía. Del lado contrario, se expresaban los sectores opuestos a cualquier apertura y al abandono de las "fronteras ideológicas". Los grupos nacionalistas anticomunistas argentinos, tales como el grupo Concentración Cívica en Pro de la República, liderado por el almirante (RE) Carlos Sánchez Sañudo, criticaron la actitud de Allende y proclamaron la defensa de la bandera de las "barreras ideológicas", poniendo en una posición muy incómoda al gobierno de Lanusse (Cisneros y Escudé, 2000).

Los fusilamientos que se produjeron el 22 de agosto fueron un elemento de peso para conceder el asilo y el traslado a los fugados. La extradición hacia un gobierno como el de Lanusse no daba ninguna garantía jurídica a los evadidos. Así lo explica una comunicación del Ministerio de Relaciones Exteriores de la República de Chile dirigida a la Delegación chilena de Naciones Unidas en Ginebra, citada por Cheren (1997: 242). El hecho creaba temores serios sobre la seguridad de los prisioneros en el caso de que fueran devueltos a la Argentina.

Cisneros y Escudé (2000) sostienen que finalmente tanto Lanusse como Allende intentaron poner "paños fríos" a la situación para que el incidente surgido no abortara el clima de acercamiento bilateral. Confirma esa idea la posición de Figueroa, como encargado de negocios, quien, a pesar de sus 
enormes diferencias ideológicas con el gobierno chileno, demuestra en sus cartas la intención de comprender lo difícil de la situación para el propio Allende. Es elocuente el hecho de que la comunicación fuera manejada por un funcionario directamente vinculado a cuestiones económicas, lo que remite a la prioridad de esos aspectos en la relación trasandina.

Las limitaciones de la estrategia de acercamiento entre gobiernos de signo tan distinto se manifestarían nuevamente en mayo de 1973 cuando Lanusse decidió firmar el decreto de asilo Walter Roberto Thieme Sheiresano y Miguel Juan Sessa Birgnardello, del movimiento ultraderechista chileno Patria y Libertad, implicados en un intento golpista contra Allende (A causa de la medida, 1973: 4).

Habría que esperar a la asunción de Héctor Cámpora el 25 de mayo de 1973 para la celebración de una coincidencia política mayor con el Chile de Allende. La complejidad del escenario interno en la Argentina ya a partir de la renuncia de Cámpora y el distanciamiento entre el gobierno peronista y el accionar de la guerrilla, preanunciarían un vínculo más distante. Sin embargo, el punto de quiebre sería el golpe de estado apoyado por los Estados Unidos que derrocaría al gobierno democrático y apoyaría su reemplazo por una dictadura neoliberal como la de Augusto Pinochet. Harmer (2103) afirma que "la Guerra Fría interamericana fue una disputa única y polifacética entre partidarios regionales del comunismo y del capitalismo, aunque en formas variadas" (pp. 8-19). Hemos afirmado aquí que esos alineamientos no son sencillos ni unívocos, sino que es necesario distinguir los aspectos económicos de los políticos, y al mismo tiempo buscar puntos de contacto.

Para finalizar, cabe destacar sobre estos terribles sucesos que rodean nuestro trabajo, que en 2014 la Cámara de Casación Penal Argentina ratificó la masacre de Trelew como delitos de lesa humanidad, lo que permitió dejar firmes penas de prisión perpetua a los responsables de esos fusilamientos.

\section{Bibliografía citada}

"A causa de la medida que favoreció a los fugados de Rawson. El asilo político a dos extremistas de Chile sería una respuesta argentina." (10 de mayo de 1973). La Opinión, p. 4.

Allende, Salvador (1971). Discurso con motivo de la visita del Presidente argentino Alejandro Lanusse. Disponible en

https://www.marxists.org/espanol/allende/1971/octubre13.htm

Ansaldi, Waldo y Giordano, Verónica (2014). América Latina. La construcción del orden (Tomo II), Buenos Aires: Ariel. 
Azcoitia, Alfredo (2017). "Argentina frente al gobierno de Allende, la mirada del diario Río Negro", Estudios Fronterizos on-line, núm. 18, Vol. 36, Mexicali, Baja California, pp. 102-125. Disponible en http://www.scielo.org.mx/scielo.php?script=sci arttext\&pid=S0187$\underline{69612017000200102}$

Binder, Axel; Guerriera, Natalia; Beovídez, José Luis y Chiquichano, Nahuel (2015). Diario Del Juicio Masacre De Trelew: a 40 años. Chubut: Fondo Editorial de la Secretaría de Cultura de Chubut.

Bologna, Bruno Alfredo (1977). "Ruptura del sistema internacional", Revista de Política Internacional, núm. 151, pp. 192- 204.

Brands, Hal (2010). "The United States and the Peruvian Challenge, 1968-1975”, Diplomacy E Statecraft, núm. 3, vol. 21, pp. 471-490.

Carella, Alfredo y Moneta, Juan Carlos (1973). “Argentina y el pluralismo en el sistema interamericano", en Petras et all (Comp.) Política de poder en América Latina, Buenos Aires: Pleamar, pp. 85-145

Carta de Figueroa, Gustavo a Mac Loughlin, Eduardo (A). (22 de agosto de 1972). Asunto: "Remitir recortes de prensa sobre terroristas fugados de Cárcel de Rawson, Santiago de Chile. AMRECA, Caja AH 0040.

Carta de Figueroa, Gustavo a Mac Loughlin, Eduardo (B). (22 de agosto de 1972). Asunto: Informar conceptos generales expresados por el Ministro de Relaciones Exteriores de Chile, Santiago de Chile. AMRECA, Caja AH 0040.

Carta de Figueroa, Gustavo a Mac Loughlin, Eduardo. (23 de agosto de 1972). Asunto: "Unión Socialista Popular. Sus ataques a la Unidad Popular. Secuestradores argentinos", Santiago de Chile. AMRECA, Caja AH 0040.

Carta de Figueroa, Gustavo a Mac Loughlin, Eduardo. (28 de agosto de 1972). Asunto: "Evaluar decisión Chile caso secuestradores del avión de la compañía Austral", Santiago de Chile. AMRECA, Caja AH 0040.

Central Intelligence Bulletin, Secret № 41, 0162/72, (7 de julio de 1972), p. 6. Central Intelligence Agency, Directorate of Intelligence CIARDP79T00975A02230010001-2.

Central Intelligence Bulletin, Secret № 41, 0208/72, (30 de agosto de 1972), p. 8. Central Intelligence Agency, Directorate of Intelligence CIARDP79T00975A022600120001-7.

Cheren, Liliana (1997). La Masacre de Trelew. Institucionalización del Terrorismo de Estado, Buenos Aires: Corregidor.

Cisneros, Andrés y Escudé, Carlos (2000). Historia General de las Relaciones Exteriores de la República Argentina, Parte III Las relaciones exteriores de la Argentina 
subordinada (1943-1989). Tomo XIV Las relaciones políticas (1966-1989), Buenos Aires: Grupo Editor Latinoamericano, Nuevo Hacer.

Corvalán, Luis (1972) "Organizar la nueva agricultura para elevar la producción. Informe al pleno del CC del PCCH, 13 de agosto de 1972", Disponible en: https://www.marxists.org/espanol/corvalan/corvalan-1972.pdf

Declaración de Salta (1971), Revista Estrategia, núm. 12, Buenos Aires, julioagosto-septiembre-octubre 1971, pp. 132-135.

De Pablo Pardo, Luis María (2016 [1988]). “Entrevista con Rapoport, Mario”, en Rapoport, Mario (2016) (comp.) Historia Oral de la Política Exterior Argentina. Tomo II. Buenos Aires: Octubre.

De Santis, D. (1998). A vencer o morir. PRT-ERP. Documentos. Tomo II. Buenos Aires: EUDEBA.

“Divergencias en Fuerzas Armadas enfrenta Lanusse." (29 de agosto de 1972). El Espectador, Archivo de Ministerio de Relaciones Exteriores y Culto, caja $\mathrm{AH} / 0118$.

“Eleváse a 16 la cifra de presos políticos asesinados por el régimen argentino." (24 de agosto de 1972). Granma, p. 7.

“En Cuba revolucionarios argentinos evadidos de la cárcel de Rawson." (28 de agosto de 1972). Granma, p. 5.

Eidelman, Ariel (2009). “El PRT-ERP y la lucha por la libertad de los presos políticos, 1971-1973", Sociohistórica, núm. 25, pp.13-39. Disponible en: http://www.memoria.fahce.unlp.edu.ar/art revistas/pr.4430/pr.4430.pdf

Eloy Martínez, Tomás (2009 [1973]). La pasión según Trelew, Buenos Aires: Alfaguara.

"Esta madrugada: declaraciones de Mor Roig." (16 de agosto de 1972). Clarín, p. 18-19.

Fermandois Huerta, Joaquín (1982). Chile y el mundo. 1970-1973, Santiago de Chile: Ediciones Universidad Católica de Chile.

Granma, 29 de agosto de 1972, p 3.

Harmer, Tanya (2013) El gobierno de Allende y la Guerra Fría Interamericana, Santiago de Chile: Ediciones Universidad Diego Portales.

"Identifican a los 10 integrantes del grupo guerrillero que desvió avión argentino a Chile." (17 de agosto de 1972). Granma, p. 5

"Inquietud de los radicales: se trata de no matar" (21 de agosto de 1972) Crónica, p.5

“Lanusse conversó telefónicamente con Allende." (16 de agosto de 1972) Clarín, p. 19. 
“Las tensiones argentino-chilenas." (28 de agosto de 1972) El Espectador, p.5.

“Matanza en Rawson influyó en la decisión de Allende." (29 de agosto de 1972) El Espectador. [AMRECA], Caja AH/0118.

Míguez, María Cecilia (2018). “El concepto de pluralismo ideológico en América Latina y la política exterior argentina (1971-1975)", Revista Análisis Político, vol. 31, núm. 94, Universidad Nacional de Colombia, pp. 93-120. Disponible en: https://revistas.unal.edu.co/index.php/anpol/article/view/78242.

Míguez, María Cecilia (2019). “Argentina y el Pacto Andino en la década de 1970: política interna y relaciones internacionales", Revista Ciclos en la Historia, la Economía y la Sociedad, núm. 52, pp. 33-62. Disponible en:

http://ojs3.econ.uba.ar/index.php/revistaCICLOS/issue/current

Moniz Bandeira, Luiz Alberto (2011). Fórmula para el caos: la caída de Salvador Allende (1970-1973), Buenos Aires: Corregidor.

Musacchio, Andrés (2006). "De la ALALC al Mercosur: la experiencia argentina", en Morgenfeld, Leandro (Comp.) El Mercosur en cuestión, Buenos Aires: Ediciones Cooperativas.

“Negarían el pedido de extradición” (21 de agosto de 1972) Crónica, p. 4.

Paradiso, José (1993). Debates y trayectorias de la política exterior argentina, Buenos Aires: Grupo Editor Latinoamericano.

Pittaluga, Roberto (2006). “La memoria según Trelew”, Sociohistórica, núm. 1920, 2006, Universidad Nacional de La Plata, Facultad de Humanidades y Ciencias de la Educación, Centro de Investigaciones Socio Históricas.

Rapoport, Mario y Laufer, Rubén (2000). “Los Estados Unidos ante el Brasil y la Argentina - los golpes militares de la década del 60", Estudios Interdisciplinarios De América Latina Y El Caribe, núm. 11, (2). Disponible en: http://eial.tau.ac.il/index.php/eial/article/view/1001

Rapoport, Mario (2016). Historia Oral de la Política Exterior Argentina, Tomo II (1966-2016), Buenos Aires: Octubre.

Reportaje, Diario Clarín, 18 de agosto de 1972, p. 13.

Scena, Miguel Angel (1981). Argentina-Chile: una frontera caliente. Buenos Aires: Editorial De Belgrano.

"Secuestra fuerzas militares del régimen fascista los restos de tres revolucionarios asesinados en la Base Naval de Trelew." (25 de agosto de 1972). Granma, p. 9

"Setenta detenidos por protestar contra Masacre de Trelew." (28 de agosto de 1972). Granma, p. 3. 
The President's Daily Brief, TOP SECRET, For the President only, Central Intelligence Agency, 17 de agosto de 1972, CIA RECORDS DOC_0005993469.

The President's Daily Brief, TOP SECRET, For the President only, Central Intelligence Agency, 23 de agosto de 1972, CIA RECORDS DOC_0005993479.

The President's Daily Brief, TOP SECRET, For the President only, Central Intelligence Agency 26 de agosto de 1972 p.7, CIA RECORDS DOC_0005993485.

The President's Daily Brief, TOP SECRET, For the President only, Central Intelligence Agency, 30 de agosto de 1972, p. 7, CIA RECORDS DOC_0005993492. 